\title{
Variables socio económicas de las economías de APEC: 1999
}

$\mathrm{E}$ l objetivo principal de este ensayo es dar al lector una visión panorámica de las 21 economías que conforman el Foro de Cooperación Económica de Asia Pacífico (APEC). Para tal fin se utilizaron 54 variables que cubren aspectos económicos, sociales, demográficos y territoriales, los cuales muestran el grado de desarrollo económico y la calidad de vida de los habitantes de estas economías.

Mismas que se clasificaron de acuerdo a su grado de desarrollo, con base al ingreso per cápita medido en dólares internacionales ${ }^{1}$ (el cual mide el poder de compra). El rango de ingreso para ubicarlas (determinado por el Banco Mundial) ${ }^{2}$ nos dio por resultado tres grupos: con alto nivel de desarrollo, intermedio y bajo.

\section{a) Economías de APEC de alto nivel de desarrollo}

Las economías que conforman el grupo de los más desarrollados, por orden descendente, son Estados Unidos, Canadá, Brunei, Japón, Australia, Hong Kong, Singapur, Nueva Zelanda, Corea del Sur y Taiwan. Estos diez países aportan el 87 por ciento del Producto Interno Bruto (PIB) total de las economías de APEC y sus habitantes cuentan con un ingreso per cápita promedio de $\$ 22,355$ dólares internacionales. Estas cifras reflejan en buena parte el desarrollo de esas naciones y el nivel de vida de los 538 millones de habitantes del grupo, los cuales representan el 21 por ciento de la población total de las economías de APEC (cuadro 1).

Uno de los rasgos que caracterizan a este grupo es la baja contribución de la agricultura al PIB -exceptuando a Nueva Zelanda, país que se distingue por poseer un eficiente sistema agrícola, generador de un alto porcentaje de ingresos por divisas. El crecimiento económico de estas economías se basa principalmente en la manufactura, las finanzas y los servicios, destacando este último en la generación de empleos.

La mitad de los países que integran este grupo presenta altos niveles de apertura (exportaciones más importaciones como porcentaje del PIB) mayores al 30 por ciento. Las de menor grado de apertura son Estados Unidos, es seguido por Japón y Australia. El comercio exterior de estos países se caracteriza por su concentración en productos manufacturados, de gran valor agregado y con tecnología de punta, exceptuando a Brunei que basa sus exportaciones en el petróleo y el gas natural, y a Australia y Nueva Zelanda que exportan sobre todo bienes agrícolas.

La eficiencia de las industrias de los países desarrollados se ve reflejada en los altos niveles de exportación, lo que los convierte en los mayores proveedores del mundo ${ }^{3}$; además, la actividad económica interna y la creación de infraestructura e instituciones les han permitido alcanzar altos niveles de bienestar económico, salud, educación, y acceso a la tecnología y a la comunicación (apartado 3 y 5 , cuadro 1 ).

La inversión extranjera directa (IED) también ha jugado un papel importante en el desarrollo de estas economías, tales son los casos de Singapur, Canadá, Estados Unidos, Corea y Taiwán. Es las que junto con el comercio ha contribuido a fomentar la actividad intereconomías de APEC (apartado 4, cuadro 1).

* Pasante de la Licenciatura en Estudios Internacionales. ORCID http://orcid.org/0000-0002-4553-8141 
Cuadro 1

Apec: economías con nivel de desarrollo alto

1999

\begin{tabular}{|c|c|c|c|c|c|c|c|c|c|c|}
\hline Variables & Estados Unidos & Canadá & Brunei & Japón & Australia & Hong Kong & Singapur & Nueva Zelanda & Corea & Taiwan \\
\hline \multicolumn{11}{|l|}{ 1-Economía } \\
\hline Producto Interno Bruto (PIB), mill dls. & $8,879,500$ & 614,003 & $7,800^{\star}$ & $4,054,545$ & 397,345 & 165,122 & 95,429 & 53,299 & 397,910 & 287,881 \\
\hline PIB per cápita, dólares & 31,910 & 20,140 & $24,630^{*}$ & 32,030 & 20,950 & 24,570 & 24,150 & 13,990 & 8,490 & 13,235 \\
\hline PIB per cápita, dólares internacionales & 31,910 & 25,440 & N.D & 25,170 & 23,850 & 22,570 & 22,310 & 17,630 & 15,530 & $14,514.9^{*}$ \\
\hline Crecimiento Promedio anual (1990-1999), (\%) & 2.00 & 1.7 & -0.5 & 1.1 & 2.9 & 2 & 4.7 & 1.8 & 4.7 & 6.3 \\
\hline Inflación promedio anual 1990-1999 (\%) & 2.1 & 1.4 & 1.1 & 0.1 & 1.3 & 5.2 & 1.6 & 1.4 & 5.8 & N.D \\
\hline Agricultura en la economía, (\%) del PIB & 1.7 & 3.0 & 3.0 & 2.0 & 3.0 & 0.1 & 0.0 & 15.0 & 5.0 & 2.6 \\
\hline Población activa, en miles & 139,368 & $15,632^{*}$ & N.D. & 67,410 & $9,343^{*}$ & $3,359^{\star}$ & $1,932^{*}$ & $1,864^{*}$ & 21,634 & 9,668 \\
\hline Empleo, en miles & 133,488 & $14,326^{*}$ & 9385 & 64,623 & $8,553^{\star}$ & $3,201^{*}$ & $1,870^{*}$ & $1,725^{\star}$ & 20,281 & 9,385 \\
\hline En la agricultura, porcentaje & 3.6 & 5.0 & 2.0 & 5.7 & 6.0 & 0.6 & 0.2 & 9.8 & 13.3 & 8.3 \\
\hline En la industria, porcentaje & 23.8 & 28.0 & 24.0 & 32.9 & 22.0 & 30.1 & 31.6 & 22.5 & 23.3 & 37.2 \\
\hline En los servicios, porcentaje & 72.6 & 67.0 & 74.0 & 61.4 & 72.0 & 69.3 & 68.2 & 67.7 & 63.4 & 54.5 \\
\hline Desempleo, en miles & 5,880 & 1,216 & N.D. & 2,787 & $747^{\star}$ & $158^{*}$ & $62^{*}$ & $139^{*}$ & 1,353 & 283 \\
\hline Inversión en la economía, Porcentaje del (PIB) & 18.5 & 19.7 & N.D. & 28.7 & 21.8 & 30.2 & 33.5 & 20.8 & 20.9 & 26.1 \\
\hline Inversión del sector privado en el total (\%) & N.D. & 89.4 & 9.5 & 78.5 & 90.4 & N.D & N.D & N.D & 79.5 & N.D \\
\hline Tasa de ahorro bruta, Porcentaje PIB & 17.1 & 21.3 & N.D. & 29.9 & 21.3 & 30.5 & 51.3 & 21.4 & 33.8 & N.D \\
\hline Gastos militares como porcentaje de PIB (1999) & 3.3 & 1.3 & 4.6 & 1 & 2.2 & N.D. & 5.7 & 1.3 & 3.4 & N.D \\
\hline Gasto público en Educación \% de PNB (1995-1999) & 5.4 & 6.9 & N.D. & 3.6 & 5.5 & 2.9 & 3 & 7.3 & 3.7 & N.D \\
\hline Gasto público en salud \% del PIB (1996-1997) & 6.5 & 6.4 & 0.8 & 5.9 & 5.5 & 2.1 & 1.1 & 5.9 & 3.7 & N.D \\
\hline 2.- Territorio, miles KM2 & $9,159.10$ & $9,221.00$ & 5.3 & 376.5 & $7,682.30$ & 1.0 & 0.6 & 268.0 & 120.4 & 14.00 \\
\hline Forestal, porcentaje 2000 I & 25 & 27 & 84 & 64 & 21 & N.D & 3 & 30 & 63 & N.D \\
\hline Promedio anual deforestación 1990-2000 (\%) & -0.2 & 0.0 & 0.2 & 0.0 & 0.0 & N.D & 0.0 & -0.5 & 0.1 & N.D \\
\hline 3.- Población, miles & 278,230 & 30,491 & 322 & 126,570 & 18,967 & 6,721 & 3,952 & 3,811 & 46,858 & 22,092 \\
\hline Habitantes por Km2, personas & 30.38 & 3.31 & 60.75 & 336.18 & 2.47 & 6,721 & $6,586.67$ & 14.22 & 389.19 & 610.49 \\
\hline Población con acceso a agua, (\%) & 100 & 100 & N.D & N.D. & 100 & N.D. & 100 & N.D. & 92 & 90.9 \\
\hline Esperanza de vida al nacer, años & 77 & 79 & 76 & 81 & 79 & 80 & 78 & 77 & 73 & 75 \\
\hline Tasa de mortalidad infantil, por 1000 nacidos vivos & 7 & 5 & 9 & 4 & 5 & 3 & 3 & 5 & 8 & N.D \\
\hline Inscripción de las niñas en primaria (\%) & 95 & 94 & 91 & 103 & 95 & 91 & 92 & 100 & 93 & N.D \\
\hline Mujer en la fuerza de trabajo (\%) del total & 46 & 46 & 35 & 41 & 43 & 37 & 39 & 45 & 41 & 40 \\
\hline Población mayor de 65 años, (\%) del total (1998) & 12.5 & 12.5 & 3 & 16.1 & 12.1 & 10.2 & 6.8 & 11.6 & 6.2 & 8.44 \\
\hline Población Urbana, (\%) del total (1998) & 76.8 & 76.9 & 71.1 & 78.5 & 84.7 & 95.4 & 100 & 86.5 & 84.5 & $56^{*}$ \\
\hline \multicolumn{11}{|l|}{ 4.- Sector externo } \\
\hline Exportaciones, millones de dólares & 686,660 & 242,820 & 2,118 & 403,690 & 56,096 & 174,719 & 115,639 & 12,594 & 145,164 & 121,308 \\
\hline Exportaciones manufacturales como \% del total & 83 & 67 & N.D & 94 & 29 & 95 & 86 & 33 & 91 & N.D \\
\hline Crecimiento1995-1999, porcentaje (\%) & 6.4 & 7.8 & N.D & 1 & 3.4 & -0.63 & 3.4 & 0.7 & 8.9 & N.D \\
\hline Importaciones, millones de dólares & $1,029,920$ & 220,064 & 1,733 & 280,370 & 65,826 & 177,878 & 104,337 & 13,029 & 116,793 & 110,771 \\
\hline Crecimiento1995-1999 (\%) & 9.0 & 7.7 & & 3.0 & 5.4 & -3.2 & 1.6 & 3.9 & 3.6 & N.D \\
\hline Importación de alimentos \% del total (1997-98) & 5 & 6 & 14 & 16 & 5 & 5 & 4 & 9 & 6 & N.D \\
\hline Comercio de bienes y servicios & & & & & & & & & & \\
\hline (exportaciones + importaciones como \% del PIB en PPP & 19.8 & 57.3 & N.D & 23.2 & 26.9 & 239.2 & 275.1 & 36.7 & 35.9 & N.D \\
\hline Balanza en cuenta corriente $\%$ del PIB & -3.6 & -0.4 & 46.2 & 2.5 & -5.7 & 6.6 & 25 & -7.9 & 6 & 2 \\
\hline Inversión extranjera directa como \% del PIB & 3 & 4 & N.D & 0.3 & 1.4 & N.D. & 8.2 & 1.4 & 2.3 & N.D \\
\hline Tipo de cambio Promedio, moneda local por dólar & 1 & 1.5 & 1.7 & 113.9 & 0.6 & 7.8 & 1.7 & 0.5 & 1188.8 & 31.3 \\
\hline Promedio 1994-1999, moneda local por dólar & 1 & 1.4 & 1.57 & 111.8 & 0.7 & 7.7 & 1.5 & 0.6 & 986.8 & 29.47 \\
\hline Ingresos por turismo, millones de dólares & 74448 & 10025 & 37 & 3428 & 7525 & 7210 & 5974 & 2083 & 6802 & N.D \\
\hline Visitantes, miles & 48491 & 19557 & 964 & 4438 & 4459 & 11328 & 6258 & 1607 & 4660 & N.D \\
\hline \multicolumn{11}{|l|}{ 5.- Otros indicadores del nivel de vida } \\
\hline Consumo de electricidad per cápita Kwh (1998), & 11,832 & 15,071 & 7,676 & 7,322 & 8,717 & 5,244 & 6,771 & 8,215 & 4,497 & N.D \\
\hline Líneas telefónicas (1999), por 1000 habitantes & 664 & 655 & 246 & 558 & 520 & 576 & 482 & 496 & 438 & N.D \\
\hline Televisiones (1996-1998), por 1000 habitantes & 847 & 715 & 638 & 707 & 639 & 431 & 348 & 501 & 346 & N.D \\
\hline Computadoras personales (1999), por 1000 habitantes & 510.5 & 360.8 & 62.1 & 286.9 & 469.2 & 297.6 & 436.6 & 328 & 181.8 & N.D \\
\hline Anfritiones de internet (1998), por 1000 habitantes & 112.77 & 36.94 & 3.79 & 13.34 & 40.09 & 12.38 & 21.2 & 35.2 & 4.01 & N.D \\
\hline médicos (1992-1995), por 100,000 habitantes & 245 & 221 & N.D & 177 & N.D & N.D & 147 & 210 & 127 & N.D \\
\hline Carreteras pavimentadas como \% del total, (1995-99) & 58.8 & 35.3 & 75 & 76 & 38.7 & 100 & 100 & 61.9 & 74.5 & N.D \\
\hline Ingreso o consumo del $20 \%$ más rico de la población (\%) & 46.4 & 39.3 & N.D & 35.7 & 41.3 & N.D & N.D. & 46.9 & 39.3 & N.D \\
\hline Ingreso o consumo del $20 \%$ pobre de la población, (\%) & 5.2 & 7.5 & N.D & 10.6 & 5.9 & N.D & N.D. & 2.7 & 7.5 & N.D \\
\hline
\end{tabular}

Fuentes: World Bank 2001,Fondo Monetario Internacional 2001; Asia-Pacific Profile1998, Pacific Economic Outlook 2000-01, Informe sobre desarrollo Humano 2000, World Development Report 1978-1998/99,www.brunei.gov.bn/about_brunei/economy.htm. Y www.stat.gov.Tw. y www.apecsec.org.sg

*Empleo y desempleo. Canadá, Australia, Hong Kong, Singapur y Nueva Zelanda son de 1998

Nota: Las exportaciones e importaciones son (fob), y de Hong Kong son a partir de 1998

**En la distribución del empleo: Estados Unidos, Japón, Corea, Taiwan, Singapur y Nueva Zelanda don datos de 199، y Canadá, Australia y Hong Kong son de 1993. 
Es importante destacar el papel del turismo en la generación de divisas en algunas economías integrantes de este grupo. El ingreso por turismo en Estados Unidos es superior al PIB de Chile, o a la mitad de las exportaciones de México. Brunei es el país que menos ingresos recibe por turismo pues representan, el .5 por ciento del PIB ${ }^{4}$

Entre los problemas que se detectan en algunas de las economías de este grupo está la distribución del ingreso, que se manifiesta en la amplia brecha que existe entre el 20 por ciento de familias más ricas y el 20 por ciento de familias más pobres de la población; En el caso de Estados Unidos, Australia y Nueva Zelanda, más de 40 por ciento de la riqueza se concentra en el 20 por ciento de la clase alta, mientras que menos del seis por ciento del ingreso nacional se concentra en el 20 por ciento de la clase baja. Por otra parte Japón presenta los mejores indicadores de distribución, ya que el 35.7 de su riqueza nacional se acumula en el 20 por ciento más rico de la población y casi el 11 por ciento del ingreso se deposia en el 20 por ciento más pobre, esto nos indica que las familias más pobres de Japón tienen mejor calidad de vida que las de los otros familias de este grupo.

Otro problema que enfrentan los países desarrollados, es el envejecimiento de la población (16 por ciento del total en Japón) lo cual implica fuertes erogaciones en seguridad social para responder a las demandas de la población mayor de 65 años ${ }^{5}$

\section{b) Economías de APEC con nivel de desarrollo intermedio}

Este grupo está conformado, de acuerdo al grado de desarrollo y en orden descendente, por Chile,
México, Malasia, Rusia, Tailandia, Perú, Filipinas y China. Independientemente del valor del PIB (muy elevado en el caso de China o muy bajo en el de Chile) son países que aún no alcanzan la madurez económica que sustente el bienestar de la mayoría de sus habitantes. Aunque a primera vista parece ser un grupo muy heterogéneo, comparten problemas económicos, sociales, institucionales y financieros similares que han frenado su desarrollo pleno (cuadro 2).

La dualidad económica que enfrentan estos países los acerca y separa del desarrollo, ya que, por un lado tienen la fortuna de contar con una amplia dotación de recursos naturales, pero, por el otro, poseen sistemas institucionales ineficientes que no les permiten aprovechar al máximo sus capacidades.

En comparación con las economías más desarro-lladas, en este conglomerado de países la participación de la agricultura en el PIB es elevada, y en países como China, Filipinas, Tailandia y Perú es la actividad que absorbe el mayor porcentaje de la fuerza de trabajo, aunque reflejan una baja productividad. El sector servicios es el segundo mayor generador de empleos en este grupo, con excepción de China. Cabe destacar el caso de Rusia que capta un alto nivel de empleo en el sector industrial, aunque con relativa baja productividad.

De acuerdo al indicador de comercio total con respecto al PIB, la economía que presenta un mayor grado de apertura en estos países es Malasia (80\%), seguida por México (36\%), Tailandia (29.4\%), Chile (24.7\%) y Filipinas (24.5\%). En el otro extremo, las de menor grado de apertura, están Rusia y China. 


\section{Cuadro 2}

Apec: economías con con nivel medio de desarrollo

1999

\begin{tabular}{|c|c|c|c|c|c|c|c|c|}
\hline Variables & Chile & México & Malasia & Rusia & Tailanda & Perú & Filipinas & China \\
\hline \multicolumn{9}{|l|}{ 1-Economía } \\
\hline Producto Interno Bruto (PIB), mill dls. & 69,602 & 428,877 & 76,944 & 328,995 & 121,051 & 53,705 & 77,967 & 979,894 \\
\hline PIB per cápita, dólares & 4,630 & 4,440 & 3,390 & 2,250 & 2,010 & 2,130 & 1,050 & 780 \\
\hline PIB per cápita, dólares internacionales & 8,410 & 8,070 & 7,640 & 6,990 & 5,950 & 4,480 & 3,990 & 3,550 \\
\hline Crecimiento Promedio anual (1990-1999), (\%) & 5.6 & 1.0 & 4.7 & -5.9 & 3.8 & 3.2 & 0.9 & 9.5 \\
\hline Inflación promedio anual 1990-1999 (\%) & 8 & 19.5 & 3.9 & 190.4 & 4.6 & 31 & 8.6 & 8.2 \\
\hline Agricultura en la economía, (\%) del PIB & 8.0 & 5.0 & 11.0 & 7.0 & 10.0 & 7.0 & 18.0 & 18.0 \\
\hline Población activa, en miles & 5,827 & $39,507^{\star}$ & 8,848 & $66,736^{*}$ & $33,352^{*}$ & $7,407^{\star}$ & $31,278^{\star}$ & 705,280 \\
\hline Empleo, en miles & 5,255 & $38,618^{\star}$ & $8,600^{\star}$ & $57,860^{\star}$ & $32,138^{\star}$ & $6,834^{\star}$ & $28,262^{\star}$ & $699,570^{\star}$ \\
\hline En la agricultura, porcentaje (\%) & 17.5 & 26.7 & 19.9 & N.D. & 40.2 & 36.0 & 41.3 & 58.0 \\
\hline En la industria, porcentaje $(\%) \quad$ ** & 24.9 & 21.1 & 32.9 & 81.4 & 22.6 & 18.0 & 14.1 & 21.0 \\
\hline En los servicios, porcentaje (\%) & 57.6 & 52.2 & 47.2 & N.D. & 37.2 & 46.0 & 44.6 & 21.0 \\
\hline Desempleo, en miles & 572 & $890^{*}$ & $284^{*}$ & $1,929 *$ & $1,138^{\star}$ & $573^{\star}$ & $3,016^{\star}$ & $5,710^{\star}$ \\
\hline Inversión en la economía, Porcentaje del PIB (\%) & 26.5 & 24.4 & 26.7 & 16.3 & 25.3 & 24.3 & 20.5 & 38.3 \\
\hline Inversión del sector privado en el total (\%) & 87.7 & 92.1 & 65.4 & N.D. & 66.2 & 84.2 & 76 & 45.8 \\
\hline Tasa de ahorro bruta, Porcentaje PIB & 25.2 & 22.4 & 48.5 & 21.2 & 41.8 & 19.5 & 16.3 & 42.6 \\
\hline Gastos militares como porcentaje de INB (1999) & 3.9 & 1.1 & 2.2 & 5.8 & 2.3 & 2.1 & 1.5 & 2.2 \\
\hline Gasto público en Educación \% de PNB (1995-1999) & 3.6 & 4.9 & 4.9 & 3.5 & 4.8 & 2.9 & 3.4 & 2.3 \\
\hline Gasto público en salud \% del PIB (1996-1997) & 2.4 & 2.8 & 1.3 & 4.5 & 1.7 & 2.2 & 1.7 & 0.7 \\
\hline 2.- Territorio, miles KM2 & 748.8 & $1,908.70$ & 328.6 & $16,888.50$ & 510.9 & $1,280.0$ & 298.2 & $9,327.40$ \\
\hline Forestal, porcentaje 2000l & 21 & 29 & 59 & 50 & 29 & 51 & 19 & 18 \\
\hline Promedio anual deforestación 1990-2000 (\%) & 0.1 & 1.1 & 1.2 & 0.0 & 0.7 & 0.4 & 1.4 & -1.2 \\
\hline 3.- Población, miles & 15,018 & 96,586 & 22,710 & 146,200 & 60,246 & 25,230 & 74,259 & $1,253,595$ \\
\hline Habitantes por Km2, personas & 20.06 & 50.60 & 69.11 & 8.66 & 117.92 & 19.71 & 249.02 & 134.40 \\
\hline Población con acceso a agua, (\%) & 94 & 86 & N.D. & 99 & 80 & 77 & 87 & 75 \\
\hline Esperanza de vida al nacer, años & 76 & 72 & 72 & 66 & 69 & 69 & 69 & 70 \\
\hline Tasa de mortalidad infantil, por 1000 nacidos vivos & 10 & 29 & 8 & 16 & 28 & 39 & 31 & 30 \\
\hline Desnutrición infantil, (\%) de bajo peso & 1 & 8 & 20 & 3 & 19 & 8 & 30 & 9 \\
\hline Población, bajo la línea de pobreza & 20.5 & 10.1 & 15.5 & 30.9 & 13.1 & 49 & 36.8 & 4.6 \\
\hline Inscripción de las niñas en primaria (\%) & 88 & 102 & 99.9 & 93 & $\star \star \star \star 89.2$ & 90 & ***99.9 & 102 \\
\hline Mujer en la fuerza de trabajo (\%) del total & 33 & 33 & 38 & 49 & 46 & 31 & 38 & 45 \\
\hline Población mayor de 65 años & 6.9 & 4.5 & 4 & 12.3 & 5.5 & 4.6 & 3.5 & 6.5 \\
\hline Población Urbana, (\%) del total (1998) & 84.3 & 74 & 55.8 & 77 & 20.9 & 72 & 56.9 & 32.7 \\
\hline \multicolumn{9}{|l|}{ 4.- Sector externo } \\
\hline Exportaciones, millones de dólares & 15,616 & 136,392 & 84,052 & 75,844 & 56,775 & 6,112 & 34,210 & 194,716 \\
\hline Exportaciones manufacturales como \% del total & 17 & 85 & 80 & 25 & 74 & 21 & 41 & 88 \\
\hline Crecimiento1995-1999, porcentaje (\%) & 6.1 & 17.5 & 8.1 & 2.3 & 5 & 5.9 & 20.5 & 13.7 \\
\hline Importaciones, millones de dólares & 13,952 & 141,973 & 61,404 & 39,625 & 42,762 & 6,729 & 29,252 & 158,509 \\
\hline Crecimiento1995-1999 (\%) & 5.1 & 12.3 & 2.1 & -4.7 & -2.4 & 3.8 & 6.5 & 10.7 \\
\hline Importación de alimentos \% del total (1997-98) & 7 & 6 & 6 & 17 & 5 & 16 & 9 & 5 \\
\hline Comercio de bienes y servicios & & & & & & & & \\
\hline (exportaciones + importaciones como \% del PIB en PPP & 23.7 & 35.6 & 80.2 & 10.6 & 29.4 & 12.2 & 24.5 & 8 \\
\hline Balanza en cuenta corriente\% del PIB & -0.1 & -2.9 & 15.9 & 5.2 & 10 & -3.5 & 10.3 & 1.6 \\
\hline Inversión extranjera directa como \% del PIB & 13.7 & 2.4 & 2 & 0.8 & 5 & 3.8 & 0.7 & 3.9 \\
\hline Tipo de cambio Promedio, moneda local por dólar & 508.8 & 9.6 & 3.8 & 24.6 & 37.8 & 3.4 & 39.1 & 8.3 \\
\hline Promedio 1994-1999, moneda local por dólar & 436.3 & 7.3 & 3.0 & 8.7 & 31.0 & 2.6 & 31.3 & 8.4 \\
\hline Ingresos por turismo, millones de dólares & 1,062 & 7,223 & 2,822 & 7,771 & 6,695 & 913 & 2,534 & 14,098 \\
\hline Visitantes, miles & 1,626 & 19,043 & 7,931 & 18,496 & 8,651 & 944 & 2,171 & 27,047 \\
\hline \multicolumn{9}{|l|}{ 5.- Otros indicadores del nivel de vida } \\
\hline Consumo de electricidad per cápita Kwh (1998), & 2,082 & 1,513 & 2,554 & 3,937 & 1,345 & 642 & 451 & 746 \\
\hline Líneas telefónicas (1999), por 1000 habitantes & 207 & 112 & 203 & 210 & 86 & 67 & 39 & 86 \\
\hline Televisiones (1996-1998), por 1000 habitantes & 232 & 261 & 166 & 420 & 236 & 144 & 108 & 272 \\
\hline Computadoras personales (1999), por 1000 habitantes & 66.6 & 44.2 & 68.7 & 37.4 & 22.7 & 35.7 & 16.9 & 12.20 \\
\hline Anfritiones de internet (1998), por 1000 habitantes & 2.03 & 1.18 & 2.16 & 1.24 & 0.34 & 0.19 & 0.13 & 0.01 \\
\hline médicos (1992-1995), por 100,000 habitantes & 108 & 85 & 43 & 380 & 24 & 73 & 11 & 115 \\
\hline Carreteras pavimentadas como \% del total, (1995-99) & 18.9 & 34.3 & 75.8 & N.D. & 97.5 & 19.8 & 19.8 & N.D. \\
\hline Ingreso o consumo del $20 \%$ más rico de la población ( & 61 & 58.2 & 53.8 & 53.7 & 48.4 & 51.2 & 52.3 & 46.6 \\
\hline Ingreso o consumo del $20 \%$ pobre de la población, (\%) & 3.5 & 3.6 & 4.5 & 4.4 & 6.4 & 4.4 & 5.4 & 5.9 \\
\hline
\end{tabular}

Fuentes: World Bank 2001,Fondo Monetario Internacional 2001; Asia-Pacific Profile1998, Pacific Economic Outlook 2000-01, Informe sobre desarrollo Humano 2000, World Development Report 1978-1998/99,www.brunei.gov.bn/about_brunei/economy.htm. Y www.stat.gov.Tw. y www.apecsec.org.sg 
La mayor parte de estas economías ha emprendido, sobre todo a partir de los ochenta, programas de apertura comercial. Los países con mayores tasas de crecimiento exportador e importador en la segunda mitad de los noventa han sido Filipinas, México y China. Con excepción de Chile, Rusia y Perú el resto de los países exporta mayormente bienes manufacturados.

Excluyendo a Rusia y Filipinas, para el resto de las economías la inversión extranjera directa representa más de $2 \%$ del PIB, destacando los casos de Chile, Tailandia, China, y Perú.

En relación a los indicadores de gasto público cabe destacar los casos de Chile y Rusia por el elevado porcentaje de presupuesto que destinan a la seguridad. En cuanto al gasto público en educación, los países que muestran mejores indicadores son México, Tailandia y Malasia, que destinan a este rubro casi el 5 por ciento del PIB, aunque está por debajo del promedio del grupo de los desarrollados. Con relación al gasto público en salud, con excepción de Rusia, el resto de los integrantes de este grupo destina entre 1 y 3 por ciento de su PIB, porcentaje también por debajo del grupo de los desarrollados. Ello se refleja en la salud de sus habitantes, sobre todo en los casos de Tailandia, Perú, Filipinas y China, que tienen una esperanza de vida de 69 años, promedio inferior al caso chileno (76 años), estos países además presentan las mayores tasas de mortalidad y desnutrición infantil del grupo. Llama la atención el caso ruso por el bajo indicador de esperanza de vida y la alta tasa de mortalidad infantil, no obstante que destina al sector salud un alto porcentaje del PIB.

Este conjunto de países comprende el 67 por ciento de la población total de APEC. De estos, Filipinas y China tienen la mayor densidad de población ${ }^{6}$. En general, este bloque se caracteriza por tener un alto porcentaje de la población bajo la línea de pobreza, con excepción de China donde representa sólo el 4.6 por ciento, aunque en términos absolutos, por el tamaño de su población, el número de personas bajo la línea de pobreza alcanzan los 58 millones. Se observa además, que en este conjunto la participación laboral de las mujeres es equivalente a la que tienen en los países desarrollados, con excepción de Perú, Chile y México, en los cuales promedia el 32 por ciento, 10 puntos porcentuales abajo con relación al primer grupo.

Los países con indicadores de pobreza más aguda son Perú, Filipinas y Rusia. Cabe destacar la desigualdad distributiva del ingreso en los integrantes del grupo, destacando las economías latinoamericanas por ser las más desiguales. En ambas, el 20 por ciento de las familias de mayores recursos absorbe el 60 por ciento del PIB y el 20 por ciento más pobre, sólo tiene acceso al 3.5 del ingreso del país. China y Tailandia por su parte, tienen una mejor distribución del ingreso.

En los países de desarrollo intermedio, sus habitantes se benefician de los avances tecnológicos y de comunicación, aunque no en la misma proporción que la población de las economías desarrolladas. La mayoría, al menos una quinta parte de la población, tienen televisores, mientras que sólo una tercera parte de los usuarios de teléfonos y televisión tienen computadoras; de éstos un porcentaje mucho menor es usuario de internet. Este no es el caso en el acceso a las líneas telefónicas, ya que en China, Tailandia, Perú y Filipinas menos del $10 \%$ tiene acceso a este servicio.

\section{c) Economías de bajo nivel de desarrollo de APEC}

De las 21 economías que conforman APEC sólo a Indonesia, Papua Nueva Guinea y Vietnam se les considera como países de menor desarrollo. Con un ingreso per cápita por debajo de los $\$ 2,700$ dólares internacionales, los tres países surgen como naciones independientes en la segunda mitad del siglo $\mathrm{XX}^{7}$ y se caracterizan por ser países ricos en recursos naturales, tales 
Apec: economías con nivel de desarrollo bajo

Cuadro 3 1999

\begin{tabular}{|c|c|c|c|}
\hline Variables & Indonesia & P. Nueva Guinea & Vietnam \\
\hline \multicolumn{4}{|l|}{ 1-Economía } \\
\hline Producto Interno Bruto, mill dls. & 125,043 & 3,834 & 28,733 \\
\hline PIB per cápita, dólares & 600 & 810 & 370 \\
\hline PIB per cápita, dólares internacionales & 2,660 & 2,260 & 1,860 \\
\hline Crecimiento Promedio anual (1990-1999), (\%) & 3.0 & 2.3 & 6.2 \\
\hline Agricultura en la economía, (\%) del INB & 19.0 & 30.0 & 25.0 \\
\hline Población activa, cifras en miles & 92,735 & N.D. & N.D: \\
\hline Empleo, cifras en miles & $87,672^{*}$ & 100 & $1031^{*}$ \\
\hline En la agricultura, porcentaje (\%) & 45.0 & 79.0 & 72.5 \\
\hline En la industria, porcentaje (\%) & 17.0 & 7.0 & 10.7 \\
\hline En los servicios, porcentaje (\%) & 38.0 & 14.0 & 16.8 \\
\hline Desempleo, cifras en miles & $5,063^{*}$ & N.D. & N.D: \\
\hline Inversión en la economía, Porcentaje del PIB (\%) & 14 & 30.3 & 21.3 \\
\hline Inversión del sector privado en el tota (\%)| & 77 & 76.9 & N.D \\
\hline Tasa de ahorro bruta, Porcentaje PIB & 24.1 & 28.3 & 21.3 \\
\hline Inflación promedio anual 1990-1999 (\%) & 14.7 & 7.1 & 16.8 \\
\hline Gastos militares como porcentaje de PIB (1999), (\%) & 2.3 & 1.3 & 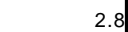 \\
\hline Gasto público en Educación \% de PNB (1995-1999), (\%) & 1.4 & N.D. & 3 \\
\hline Gasto público en salud \% del PIB (1996-1997) & 0.6 & 2.6 & 0.9 \\
\hline 2.- Territorio, miles KM2 & $1,811.60$ & 452.9 & 325.5 \\
\hline Foresta, porcentaje 2000 & 58 & 68 & 30 \\
\hline Promedio anual de deforestación 1990-2000 (\%) & 1.2 & 0.4 & -0.5 \\
\hline 3.- Población, miles & 207,022 & 4,705 & 77,515 \\
\hline Habitantes por Km2, personas & 114.28 & 10.39 & 238.14 \\
\hline Población con acceso a agua, (\%) & 76 & 42 & 56 \\
\hline Esperanza de vida al nacer, años & 66 & 58 & 69 \\
\hline Tasa de mortalidad infantil, por 1000 nacidos vivos & 42 & 58 & 37 \\
\hline Desnutrición infantil, (\%) de bajo peso & 34 & N.D & 37 \\
\hline Población, vividos en la línea de pobreza & 27.1 & N.D & 50.9 \\
\hline Inscripción de las niñas en primaria (\%) & 93 & *72.5 & *99.9 \\
\hline Mujer en la fuerza de trabajo (\%) del total & 41 & 42 & 49 \\
\hline Población mayor de 65 años, (\%) del total (1998) & 4.5 & 3 & 5.2 \\
\hline Población Urbana, (\%) del total (1998) & 38.3 & 16.8 & 20 \\
\hline \multicolumn{4}{|l|}{ 4.- Sector externo } \\
\hline Exportaciones, millones de dólares & 51,242 & 19,274 & 11,540 \\
\hline Exportaciones manufacturales como \% del total & 54 & 9 & N.D. \\
\hline Crecimiento1995-1999, porcentaje (\%) & 4.9 & -6.2 & N.D. \\
\hline Importaciones, millones de dólares & 30,598 & 10,714 & 11,622 \\
\hline Crecimiento1995-1999 (\%) & -1.1 & -4.2 & N.D. \\
\hline Importación de alimentos \% del total de mercaderia (1997-98) & 11 & N.D & N.D. \\
\hline Comercio de bienes y servicios & & & \\
\hline (exportaciones + importaciones como \% del PIB medido en PPP & 12.3 & 27.5 & 16 \\
\hline Balanza en cuenta corriente\% del PIB & 4.1 & 3.3 & -0.2 \\
\hline Inversión extranjera directa como \% del PIB & -1.9 & 8.3 & 5.6 \\
\hline Tipo de cambio Promedio, moneda local por dólar & 7,855 & 0.4 & 14,000 \\
\hline Promedio 1994-1999, moneda local por dólar & 4,588 & 0.6 & 12,703 \\
\hline Ingresos por turismo, millones de dólares & 4,045 & 104 & 86 \\
\hline Visitantes, miles & 4,700 & 70 & 1,782 \\
\hline \multicolumn{4}{|l|}{ 5.- Otros indicadores del nivel de vida } \\
\hline Consumo de electricidad per cápita Kwh (1998), & 320 & 2430 & 232 \\
\hline Líneas telefonica (1999), por 1000 habitantes & 29 & 13 & 27 \\
\hline Televisiones (1996-1998), por 1000 habitantes & 285 & 24 & 180 \\
\hline Computadoras personales (1999), por 1000 habitantes & 9.1 & N.D. & 8.9 \\
\hline Anfritiones de internet (1998), por 1000 habitantes & 0.07 & 0.03 & N.D \\
\hline médicos (1992-1995), por 100,000 habitantes & 12 & 18 & N.D \\
\hline Carreteras pavimentadas como \% del total, (1995-99) & 46.3 & 3.5 & 25.1 \\
\hline Ingreso o consumo del $20 \%$ más rico de la población (\%) & 44.9 & 56.5 & 44.5 \\
\hline Ingreso o consumo del $20 \%$ pobre de la población, (\%) & 8 & 4.5 & \\
\hline
\end{tabular}

Fuentes: World Bank 2001,Fondo Monetario Internacional 2001; Asia-Pacific Profile1998,

Pacific Economic Outlook 2000-01, Informe sobre desarrollo Humano 2000, World Development Report 1978-1998/99,

www.brunei.gov.bn/about_brunei/economy.htm. Y www.stat.gov.Tw. y wwwapecsec.org.sg 
como gas, carbón, productos marítimos, petróleo crudo, caucho, madera para construcción; y oro, plata y cobre para el caso de Indonesia y Papua Nueva Guinea (cuadro 3).

El territorio de estos tres países es equivalente, al de los de Brunei, Japón, Hong Kong, Singapur Taiwán, Nueva Zelanda, Chile, Malasia, Tailandia y Filipinas juntos, del cual el 52 por ciento es zona forestal, por lo que la producción de madera para construcción es tan importante para Indonesia como para Papua Nueva Guinea. En cuanto a la infraestructura carretera, en Indonesia el 46 por ciento está pavimentada, mientras que en Papua Nueva Guinea y en Vietnam, sólo 3.5 y el 25 por ciento respectivamente.

Destaca Vietnam en el grupo por el elevado crecimiento per cápita en la década de los noventa, de $6.2 \%$ promedio anual, debido principalmente a la reorientación de su política económica, en la que aplicó en la década de 1986 a 1996, las reformas que ellos denominaron «doi moi» o renovación, entre las que son notorias la descolectivización de la agricultura, que produjo mayor sentido de pertenencia, y el nuevo avance de la inversión de la industria pesada a la agricultura. Otras reformas no menos importantes fueron la liberalización del comercio exterior, de la inversión extranjera directa y de la tasa de interés.

Como se observa en el cuadro 3, el sector más importante en estos países es el agrícola, especialmente en Papua Nueva Guinea y Vietnam, que emplean a más de las tres cuartas partes de la población, siguiendo con un amplio margen el sector servicios y en última instancia la industria. En el caso de Indonesia, el 45 por ciento de la fuerza de trabajo se emplea en la agricultura y le siguen muy de cerca los servicios. Dada la contribución de la agricultura al PIB (entre 20 y 30 por ciento) es evidente la baja productividad de la mano de obra empleada en el campo y por ende sus bajos ingresos.
La producción agrícola de Vietnam está constituida principalmente por arroz, caucho, frutas, vegetales, maíz, azúcar, yuca, anacardos, café y pescado, mientras que en el sector industrial sobresalen los alimentos procesados, textiles, cemento, fertilizantes, químicos, acero y electricidad. En Papua Nueva Guinea destacan la producción de café, de aceite de coco procesado, de té y de madera, en el sector primario; en el industrial sobresalen la copra conglomerada, el aceite de coco procesado, cobre, oro y plata; en menor escala, produce cerveza, jabón, ropa, productos de concreto y papel, fósforos, nieve, muebles y pintura. En Indonesia sobresale la producción de madera, caucho, arroz, aceite de coco y café, en el sector agrícola; en el de los bienes manufacturados se producen prendas de vestir, calzado, electrónicos, muebles y productos de papel. De los tres, Indonesia es el que ha avanzado más en el proceso industrializador.

Uno de los factores que afectó seriamente la economía de estos países, y que elevó considerablemente la inflación, fue la crisis económica y financiera asiática de 1997. Indonesia se vio adicionalmente afectada por la peor sequía en 50 años, la caída de los precios del petróleo, el gas y de otras mercancías de exportación. En el caso de Vietnam la crisis de 1997 se vio reforzada por el relativo alto nivel de la deuda externa y el elevado déficit en cuenta corriente.

\section{Condiciones de vida}

El apartado del cuadro 3 nos revela las condiciones de vida de los habitantes de estos países. Cada una de las variables muestra el bajo nivel de bienestar de la gran mayoría de la población. La tasa de mortalidad infantil es muy alta; de los que sobreviven un buen número padece desnutrición infantil y vive en la pobreza, mientras las niñas tienen menos oportunidad de ir a la escuela, exceptuando en el caso de Vietnam, donde a pesar de que más de la mitad de sus habitantes viven bajo la línea de la pobreza, todos tienen oportunidad de estudiar, 
al menos la primaria. Un dato a resaltar es el alto porcentaje femenino en la fuerza de trabajo, similar al de los países más desarrollados. El cuadro 3 nos muestra que el 75 por ciento de la población económicamente activa está en la zona rural, de lo que se deducimos que casi la mitad de las personas que trabajan en el campo son mujeres (apartado 3 y 5,cuadro 3 ).

\section{Sector externo}

El total de las exportaciones de los tres países juntos suman 82,056 millones de dólares, similar al nivel de exportaciones de Malasia. Las principales exportaciones de Indonesia son petróleo, gas natural, madera triplay, prendas de vestir, calzado, electrónicos, muebles y productos de papel. Estos productos son colocados en Japón, Singapur, Taiwán, Corea y Estados Unidos. Las importaciones están compuestas por alimentos, químicos, bienes de capital y bienes de consumo. Sus mayores proveedores son Japón, Estados Unidos y Tailandia.

Vietnam, por su parte exporta petróleo crudo, textiles, productos marinos, arroz -es el segundo mayor exportador de arroz en el mundoy carbón. Sus socios comerciales más importantes son Japón, Singapur, Alemania, Australia y China; importa petróleo procesado, productos de acero, equipo de transporte, químicos, fertilizantes, medicinas y algodón crudo, principalmente de Japón, Corea del Sur, Francia y Taiwán.

Las exportaciones de Papua Nueva Guinea son oro, cobre, petróleo, madera, aceite de coco y café. Sus mayores socios comerciales son Australia, Japón, Alemania, Reino Unido, Corea del Sur y China; importa principalmente maquinaria y equipo de transporte, bienes manufacturados, comida, combustible y químicos, principalmente de Australia, Singapur, Japón, Estados Unidos, Nueva Zelanda y Malasia.
Observemos también que tanto para Papua Nueva Guinea como para Vietnam, la inversión extranjera directa, desempeña un papel importante en su desarrollo. El turismo genera para este grupo 4,235 millones de dólares, destacando Indonesia (ver cuadro 3).

En general, las economías de APEC, a pesar de su desigualdad económica y tecnológica, y las diferencias sociales y culturales, han llevado a cabo en el transcurso de los años sus dos principales propósitos: promover el libre comercio y poner en marcha prácticas de cooperación económica en la región. Como resultado se ha desarrollado un gran dinamismo económico y un sentido de comunidad, que los ha llevado a convertirse en la zona de mayor crecimiento económico del mundo, con un PIB total de 18 trillones de dólares en 1999 y con 43.85 por ciento del comercio global.

\section{Notas}

1 Excepto Brunei Darussalam para el que, por falta de información, utilicé el ingreso per cápita medido en dólares estadounidenses.

2 Ingreso menor a $\$ 2995$ dólares internacionales =nivel de desarrollo bajo; entre 2995 y $9265=$ medio; mayor de 9266= alto.

3 Es importante mencionar que a pesar de ser los grandes proveedores del mundo, Estados Unidos, Hong Kong y Nueva Zelanda tienen déficit comercial.

4 Los visitantes se clasifican de entre hombres negocios, turismo, compradores, entre otros.

5 El porcentaje de la población mayor de 65 años es muy elevado en Japón, Estados Unidos, Canadá, Australia, Nueva Zelanda.

6 El gobierno chino, está tomando medida para el control natal mejor conocido como el programa "un niño por familia"

7 Indonesia proclamó su independencia el 17 de Agosto de 1945, Vietnam el 2 de septiembre de 1945 y Papua Nueva Guinea el 16 de septiembre de 1975. 